\title{
Skills Gap, Innovation, and Firms Performance in Zambia
}

\author{
Yordanos Gebremeskel $^{1}$, Bupe Simuchimba ${ }^{1} \&$ Chonzi Mulenga $^{1}$ \\ ${ }^{1}$ Department of Economics, Mulungushi University, Zambia \\ Correspondence: Yordanos Gebremeskel, Department of Economics, Mulungushi University, Zambia. E-mail: \\ yorsink@yahoo.com
}

Received: July 2, 2019

Accepted: July 26, 2019

Online Published: July 30, 2019

doi:10.5539/ijef.v11n8p129

URL: https://doi.org/10.5539/ijef.v11n8p129

\begin{abstract}
This study examines the interaction between employees' skill, innovation and firm's performance. A skilled labour force has a significant impact on the innovation, performance and long-term competitiveness of the firm. Due to a weak educational system coupled with limited training facilities, most Zambian firms still face challenges in acquiring the required skilled workforce. The World Bank Skills Survey Zambia 2016 is used for the empirical analysis on 350 small, medium, and large enterprises. A binomial logit model is used for the innovation model and OLS regression model for performance measurement. We employ sales growth as a measure of firm performance. The results show that the number of professional \& skilled employees and trainings were important factors of innovation. Furthermore, we find that innovation and location have an impact on the firms' performance as measured by sales growth.
\end{abstract}

Keywords: skills-gap, trainings, innovation, sales growth, Zambia

\section{Introduction}

With only an estimated 229 students per 100,000 inhabitants in 2012, Zambia ranked among the African countries with the lowest rates of participation in higher education - a ranking only better than Seychelles and Malawi in the Southern African region, however, way below the Southern African average of 444 students per 100,000 inhabitants in higher education (UNESCO, 2016). Education and in particular higher education is seen to carry out a significant role in enhancing a country's social economic development i.e. it builds peoples abilities in terms of skills and the capability to receive and process information for livelihood choices which are useful attributes in the labour market. Although somewhat complex, there is a strong relationship between education and employment (labour market). The complexity arises from the mere fact that there are two diverse but highly interrelated entities at play; on the one hand the labour markets with a preconceived set of perceptions, attitudes and expectations while on the other hand is the outputs of the education system with attributes of their own. The expectations from these two groups are more often a stark contrast of one each other hence the resulting complications. The expectations from the labour markets are usually in respect of their job requirements, promotion and recruitment practices, job description mechanisms, and salary structures, while the expectations of the graduates from the education system are often in respect of the availability of jobs, salary structure, job security, and other conditions of service, namely, region of work, health benefits, promotion prospects, provision for self-development, to mention only a few. Due to these diverse expectations, there frequently arise a problem as to whether the training received by the graduates or outputs from the education system is relevant or in line with the job requirements of the labour markets.

Firms in Zambia are facing low growth rates. The low growth rates are due to the various challenges they are facing in the process of their business operations. These challenges include low or mismatched skills, poor infrastructure, limited access to credit, competition from foreign firms, energy deficits as well as high production costs. These have affected firms' ability to keep up with the country's growing and changing needs. This research focuses on skills and how it affects firms' performance. The level of skills in existence in the country is due to the educational attainment of most people in the labour force. Growth theories widely discussed the role of technology, physical and human capital in achieving a high level of productivity in the production of goods and services. Human capital represents the skills that workers acquire through some form of training. Various skills are important at all levels of production and in the operations of a firm. Despite being aware of the importance of skills in a firm's productivity, most developing countries face challenges in the supply of skilled workforce. This human capital requires having a given level of skills in order to be absorbed by employers. 
According to the 2014 Zambia Labour Force Survey (ZLFS), most of the economically active population possesses primary education with $41.6 \%$ followed by secondary education with $40.9 \%$ (CSO, 2016). Furthermore, it is estimated that for every 100 primary school children approximately only 1 will enrol in a tertiary institution (UNDP, 2016). Undeniably, this will have implications on the number of skilled workers available for firms to employ. Firms will still require workers provided that most of the firms in Zambia are labour intensive. The current situation implies the firms are supplied with low skilled workers and due to their need for workers, the mismatched between required skills and available jobs cannot be avoided. Firms are "forced" to employ workers from the available pool in the labour force which may affect their productivity and hence the entire economy.

Well-functioning firms have the ability to contribute positively to employment creation and social well-being. For instance between 2005 and 2014, firms in the manufacturing sector experienced an increase in the number of people employed from 166,143 to 223,681, respectively (MONP, 2017). This employment creation potential has the ability to positively affect people's living standards. It had been observed that due to the collapse of the manufacturing sector's output, there was a regression in human development indicators (UNDP, 2016). Most people in Zambia are engaged in unproductive activities that do not generate sufficient income on a regular basis (UNDP, 2016). This can change, with the successful implementation of well-targeted policies towards firms to ensure that low-level or mismatch of skills is adequately dealt with.

Zambia's labour force is described by high representation in the informal sector against the formal sector employment. The informal sector employs $90 \%$ of the labour force. The role of the private sector in employment is significant with employment levels of $92 \%$ in the informal sector and $49 \%$ in the formal sector (CSO, 2016). The liberalization program in Zambia has made it easy in fostering a conducive environment for new business establishments starting early 1990's. Lack of reliable data is a challenge to estimate how many jobs are created every year in the country. Nevertheless, most empirical works show that the informal sector is disproportionately expanding against the formal sector. The other publicly unavailable data is the exact number of formal and informal enterprises operating in the economy. Shah (2012) estimated that there are approximately 1.05 million micro, small, and medium enterprises in Zambia of which the share of the formal sector is $28 \%$. The author's estimation of the number of microenterprises shows that there are 6,058 in Lusaka, 6,432 in Kitwe, 5,970 in Ndola, and 3,359 in Livingstone. The World Bank's Zambia Enterprise Skills Survey 2016, on which most of our analysis is conducted, data is collected from these four cities. The sample size was 350 which approximately represents $1 \%$ of the number of formal enterprises as per Shah's estimation.

In this study first we examine the interplay among employees' skill, qualifications, and adoption of new products or services innovation. Secondly, we will identify the determinants of firms' performance. The study will also assess the skill requirements and shortages among firms. This study aims to provide information that will be effective in targeting the elements that are required in strengthening the performance of firms.

\section{Literature Review}

Empirical works in economics have concluded that the workers' skill has impact on the productivity, profitability and long-term competitiveness of the firm. Economists define this important resource as human capital. Blundell et al. (1999) established that there are three types of human capital. The first is what is refereed as ability that is acquired or innate. The second is the qualifications and knowledge acquired through any form of formal education. The third type is composed of skills, competencies expertise acquired through training on the job. Education and training are influenced by policies, institutions, and the economic structure and are viewed as a process of investment in manpower that determines the performance of firms. While education lay-down the foundation, training on the other hand leads to the acquisition of the required skills in the production process. The acquisition of relevant skills results in improvement of worker productivity (Mincer, 1962). In a free-market system, where the price of (wage) is comparable to the marginal product of labour, the better educated workers tend to be more productive and positively affect the profitability and competitiveness of the firm.

Soderbom and Teal (2004) analyze factors affecting poor performance in Ghana's manufacturing firms. They consider lack of skills and extent of scale, technical and allocative inefficiency. In doing so, they use the stochastic frontier model, despite the fact that it requires parametric assumptions or assumptions about the functional relationship between inputs and output. The results suggest that education causes no significant effect on productivity once controls for fixed effects and endogeneity are introduced. The results also suggest that large firms that use more capital intensive technology experience higher relative costs than small firms.

Although Ahmed and Ahmed (2013) employ a similar methodology as that used by Soderbom and Teal (2004), they do not exclusively look at the role skills play in determining variations in firms' productivity. They consider 
a case study of seafood processing firms in efficiency variation of firms in Bangladesh. The study findings suggest that firms can increase production using similar technology without facing increasing costs. The study also discovers that younger and smaller firms enjoy higher production efficiency than larger and older firms.

Blyde (2016) looks at the impact of training employees on the firm's export status for firms in Chile. The study uses a difference-in-difference estimator that considers firms export status before and after training their employees while comparing them with those that have not trained their staff. The study findings suggest that training of employees at least doubles the average rate of a firm being an exporter. The study findings also suggest that the effect depends on the amount spent on training as a percentage of the firm's total sales. However, finding that there is no difference in results between training more productive workers versus training more not productive workers. This implies that training by type does not lead to significant differences in a firm entering the export market.

Edjigu (2016) analyses firm growth and efficiency of manufacturing firms in Ethiopia. The study concentrates on how firm size and financial constraint affects firm growth as well as examines the presence of differences in efficiency across firms. The paper uses census data for the period 2000-2008. The study findings suggest that small and young firms tend to grow faster than large and old firms. This finding is similar to that obtained by Ahmed and Ahmed (2013). However, Edjigu (2016) discover that leverage and cash flows are binding constraints for the small firms.

Zhang et al. (2018) at the connection between open innovation and firm profitability. In doing so, they equally consider the role that human capital plays in the relationship between open innovation and firm profitability. They carry out this analysis on the financial statement data of mechanical manufacturing firms in china using panel data least squares regression model. The study findings show that the quality of human capital can affect the relationship between open innovation and firm profitability. Similar to that discovered by Blyde (2016), the study shows that the higher the education of employees the better the financial performance of the firm.

\section{Method and Data}

\subsection{Measuring Firm Performance}

The theoretical methodology of our research will be based on the traditional (orthodox) maximization model of firm behaviour. Nelson and Winter (1997) stated that the model contains three components. These are what the firm is seeking to maximize - usually profit or sales; set of things the firm know how to do and other resources; and choice of action given the objective, alternative actions, market constraints and internal challenges. The model helps us to understand the behaviour of business firms, their capabilities and the limits.

Modeling growth at firm level is a complex exercise. The determinant factors are many and their effect vary widely (Freel \& Robson, 2004.) Neverthless, many researchers agree that there are key variables that consistently predict performance. This study uses regression analysis to estimate a sales growth regression model. The model estimation involves analysis of the effect of the firm's internal and external factors impact on sales growth/performance. Following Sleuwaegen and Goedhuys (2002), and Rijkers et al. (2009) growth will be modeled as a function of firm-level factors, external variables, and skill \& innovation indicators.

We defined the dependent variable sales growth, like ( (Ayyagari, Demirguc-Kunt, \& Maksimovic, 2011) and Evans, 1987) as a difference in logarithm of annual sales between two years and divided by 3 . The survey has compiled annual sales data at the end of the fiscal year 2015 and at the end of the fiscal year 2013.

$$
\text { logsalesgrowth }=\frac{\ln \left(\text { Sales }_{2015}\right)-\ln \left(\text { (ales }_{2013}\right)}{3}
$$

Our OLS regression model will take the form:

$$
\text { logSalesgrowth } h_{i t}=\alpha+\delta W_{i t}+\beta X_{i t}+\gamma V_{i t}+\varepsilon
$$

Where, $\operatorname{logSalesgrowth}_{i t}$ is the natural logarithem of sales growth of firm $i$ at time $t, W_{i t}$ is skills \& innovation variables, $X_{i t}$ captures firm-level (internal) factors, $V_{i t}$ is used to asses impact of external factor such as location, and $\varepsilon$ is a normally distributed zero-mean error term.

\subsection{Innovation}

On the other hand, to analyze the impact of firm specific factors on innovation performance, we estimate a probit model:

$$
\text { Innovation }_{i t}=\alpha+\delta W_{i t}+\beta X_{i t}+\varepsilon_{i t}
$$

Where Innovation $_{i t}$ is innovativeness of firm $i$ at time $t, \alpha$ is the constant term, $W_{i t}$ is employees skill measuring variables, $X_{i t}$ are firm specific variables, and $\boldsymbol{\varepsilon}$ is the error term. 


\subsection{The Data}

The data for this study comes from The World Bank Zambia Firm-Level Skills Survey 2016. We use this data to analyze the relationship between training, innovation, and performance. The dataset represents 350 firms from four cities of Zambia. The sample includes firms from manufacturing, services, and retail sectors. These firms are categorized as 211 small firms, 105 medium size firms, and 34 large firms. Small firms are those with $5-19$ workers, medium firms are with 20 - 99 workers, and large firms have those with more than 90 workers. This data covered 8 economic activities; food processing, textile and garments, fabricated metal products, furniture, construction, hotel and restaurant, transport and IT; from four cities namely Lusaka, Livingstone, Kitwe, and Ndola.

\section{Results and Discussion}

\subsection{Descriptive Statistics}

While there are ample empirical works globally on the relationship between skills and firm's performance, we found few and scanty evidence on Zambian context. Our goal in this study is to empirically assess the impact of skill mix on small, medium, and large (SML) firms' performance. More precisely, we examine if there is a significant relationship between, training, product or service innovation, and sales growth.

\subsection{Skills Assessment and Shortage}

The total number of permanent full-time workforce represented by the sample included a total of 11,758 . Of which 2,715 are from small, 5,494 from medium, and 3,549 from large firms. There were 1,921 with primary school of below, 1,829 with lower secondary school, 3,953 with upper secondary school, and 4,046 with tertiary education qualifications. Table 1 gives a percentage of workers acquired skills as assessed by managers. Assessing the existing workforce for different skills, managers claimed that for some skill like English skill and Computer or general IT skills up to $15 \%$ and $20 \%$, respectively, of the workers have skills that are below the required level. Most are evaluated as with the required skill and some as higher than the required skill.

Table 1. Workers acquired skills as measured by managers

\begin{tabular}{lccc}
\hline Skill type & Below required & As required & \multicolumn{2}{c}{$\begin{array}{c}\text { Above required } \\
(\boldsymbol{\%})\end{array}$} \\
\hline Work ethic & 5.43 & 82 & 12.57 \\
Problem solving skills & 6.86 & 83.14 & 9.43 \\
Critical thinking skills & 7.43 & 82.86 & 9.14 \\
Interpersonal and communication skills & 10 & 85.14 & 4.86 \\
Writing skills & 10 & 79.71 & 10.29 \\
Numeracy skills & 11.14 & 82.86 & 5.14 \\
Technical skills, other than computers & 13.71 & 75.14 & 7.71 \\
English skills & 15.14 & 79.43 & 5.43 \\
Computer/General IT skills & 20.86 & 68 & 6.57 \\
\hline
\end{tabular}

We expect education and possession of the right training to make workers most preferred for employment as compared to those who lack the duo. An educated job applicant with multi-skilling are what most employers looking for skill-based jobs. Employers were also asked to rank skills as the first, second, and third most important type of skills for deciding whether or not to recruit an employee. The identified indicators of skill are interpersonal \& communication skills, work ethic, technical skills, critical thinking, problem solving, writing skills, computer/general IT skills, and numeracy skills. Only few of them stands as the most valued by the majority of the employers. Interpersonal \& communication skills, work ethic, and technical skills found to be the first most important valued skills by $36.57 \%, 19.71 \%$, and $18.29 \%$ of the respondents respectively. Work ethic with $22.29 \%$, problem solving skills with $22 \%$, and interpersonal \& communication skills with $18.57 \%$ of respondents is the second most important skills for employability. As a third most important skills work ethic (21.43\%), interpersonal and communication skills (13.43\%), and problem solving skills $(17.71 \%)$ have dominated the responses. Figure 1 presents the first most important skills for recruiting an employee. 


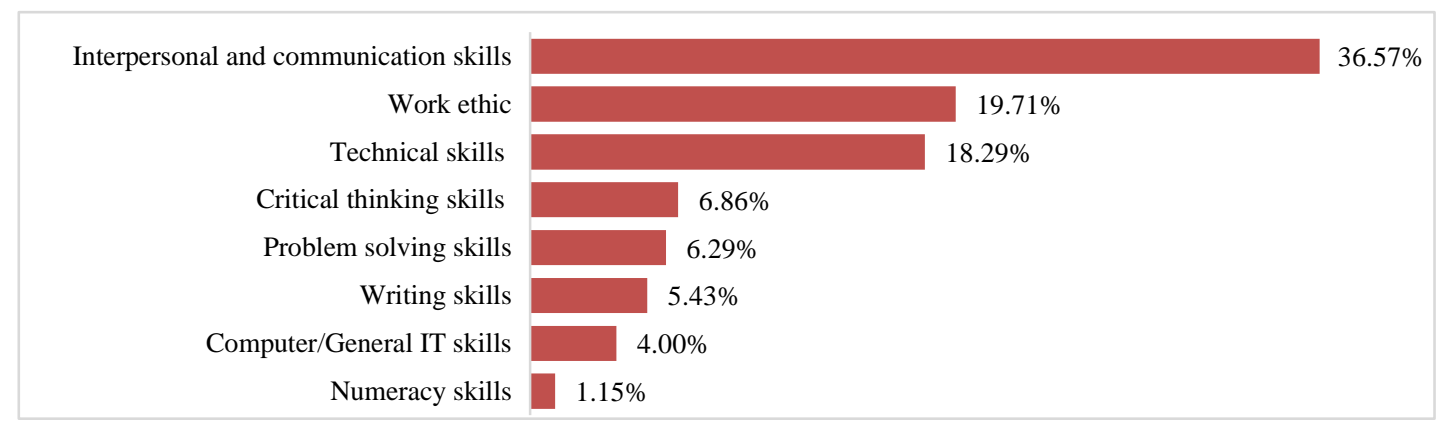

Figure 1. The first most important skill as indicated by firms

Vacancy duration and unfilled positions are used as a measure of skill shortages by some empirical works (for instance, Haskel \& Martin, 1993). Respondents were asked whether there were any job vacancies in their establishments over the last two completed fiscal years. Figure 2 shows that managerial positions (37.5\%) have the highest unfilled percentage followed by professionals (78\%).

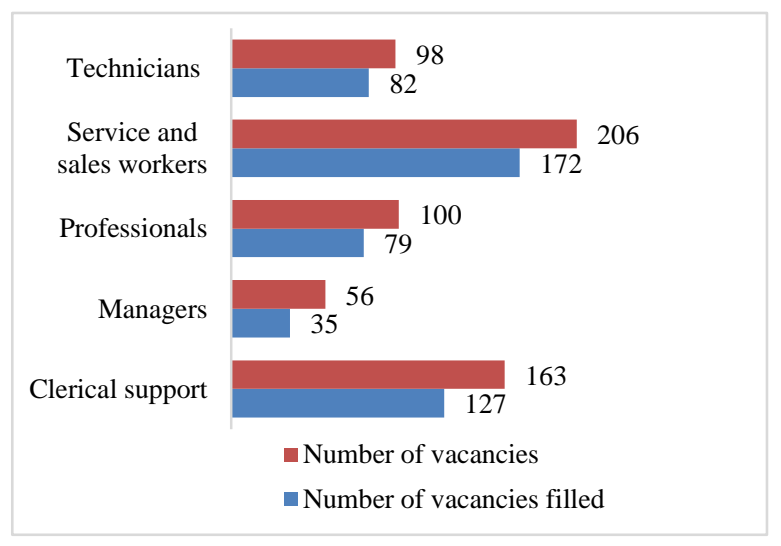

Figure 2. Total number of vacancies and filled positions (121 firms)

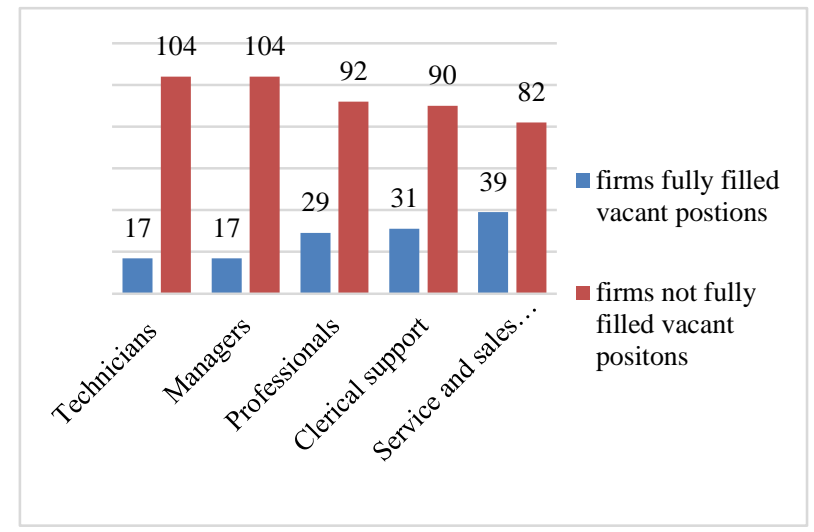

Figure 3. Number of firms and their success in filling vacant positions

\subsection{Effects of Skills Deficit}

The survey assessed whether firms faced difficulties in maintaining production levels according to demand, maintaining consistent quality, implementing a new technology or improving production processes, developing new products, and effective sales and marketing. Table 2 shows that, of the firms surveyed, $26.57 \%$ revealed that they had difficulties in maintaining planned production or/and quality, consistently. On the other hand $31.43 \%$, $24.57 \%$ and $34.29 \%$ reported difficulties of implementing new technology or improving production processes, developing new products, and effective sales and marketing, respectively.

Table 2. Difficulties due to employees' shortage of skills

\begin{tabular}{lccccc}
\hline Difficulties faced & & $\begin{array}{c}\text { Small } \\
(5-19)\end{array}$ & $\begin{array}{c}\text { Medium } \\
(20-99)\end{array}$ & $\begin{array}{c}\text { Large } \\
(100+)\end{array}$ & All firms \\
\hline Maintaining production levels according to & Yes & $6128.91 \%)$ & $24(22.86 \%)$ & $8(23.53 \%)$ & $93(26.57 \%)$ \\
demand & No & $146(69.19 \%)$ & $79(75.24 \%)$ & $25(73.53 \%)$ & $250(71.43 \%)$ \\
\multirow{2}{*}{ Maintaining consistent quality } & Yes & $58(27.49 \%)$ & $30(28.57 \%)$ & $5(14.71 \%)$ & $93(26.57 \%)$ \\
& No & $152(72.04 \%)$ & $75(71.43 \%)$ & $29(85.29 \%)$ & $256(73.14 \%)$ \\
Implementing new technology or improving & Yes & $66(31.28 \%)$ & $34(32.38 \%)$ & $10(29.41 \%)$ & $110(31.43 \%)$ \\
production processes & No & $141(66.82 \%)$ & $71(67.62 \%)$ & $24(70.59 \%)$ & $236(67.43 \%)$ \\
Developing new products & Yes & $53(25.12 \%)$ & $28(26.67 \%)$ & $5(14.71 \%)$ & $86(24.57 \%)$ \\
& No & $155(73.46 \%)$ & $77(73.33 \%)$ & $29(85.29 \%)$ & $261(74.57 \%)$ \\
Effective sales and marketing & Yes & $79(37.44 \%)$ & $32(30.48 \%)$ & $9(26.47 \%)$ & $120(34.29 \%)$ \\
& No & $132(62.56 \%)$ & $71(67.62 \%)$ & $25(73.53 \%)$ & $228(65.14 \%)$ \\
\hline
\end{tabular}




\subsection{Training to Improve Skills}

The human capital is a key resource for any enterprise. Training (in-house and external) plays a critical role in empowering employees with the required skills needed which would be translated to productivity and better performance. Table 3 shows that roughly a quarter of employees (26\%), out of the total 350 , received formal training. It is also depicted that most of the training, $85 \%$, was conducted in-house.

Table 3. Employees trainings by size of firms

\begin{tabular}{llcccc}
\hline & & Small & Medium & Large & All firms \\
\hline \multirow{2}{*}{ Formal training programs } & Yes & $49(23 \%)$ & $36(34 \%)$ & $6(18 \%)$ & $91(26 \%)$ \\
& No & $162(77 \%)$ & $69(66 \%)$ & $27(82 \%)$ & $258(74 \%)$ \\
\multirow{2}{*}{ In-house training } & Yes & $42(86 \%)$ & $30(83 \%)$ & $5(84 \% 0$ & $77(84 \%)$ \\
& No & $7(14 \%)$ & $6(17 \%)$ & $1(16 \%)$ & $14(16 \%)$ \\
\hline
\end{tabular}

\subsection{Innovation}

Table 4 presents the use of technology and innovation by the firms. More than half of the small firms reported that they have introduced one or more of the innovation and technology indicators as compared to a low percentage by medium and large firms.

Table 4. Innovation and technology use

\begin{tabular}{lcc}
\hline & Yes & No \\
\hline Introduced new product or services & $198(56.57 \%)$ & $150(42.86 \%)$ \\
New production method & $187(53.43 \%)$ & $161(46 \%)$ \\
New logistics, delivery, or distribution & $176(50.29 \%)$ & $173(49.43 \%)$ \\
New organization or management practice & $137(39.14 \%)$ & $212(60.57 \%)$ \\
New marketing methods & $225(64.29 \%)$ & $124(35.43 \%)$ \\
\hline
\end{tabular}

\subsection{Regression Results}

\subsubsection{Innovation Performance}

According to Dostie (2014), four measures could be used to assess the existence of innovation at the workplace level. These are new products or services, improved products or services, new processes, or improved processes. Furthermore, OECD (2005) defined innovation as "A product innovation is the introduction of a goods or services that are new or significantly improved with respect to its characteristics or intended uses. This includes significant improvements in technical specifications, components and materials, incorporated software, user-friendliness or other functional characteristics."

In the WB enterprise survey under the section 'Innovation and Technology use', firms are asked about the introduction of new products, improved methods of manufacturing products, improved logistics method, and improved management and marketing practices in the past 3 years. The focus of our innovation performance analysis will be on two questions. These are:

(1) If the establishment introduces new or significantly improved products or services, and

(2) If the establishment introduced any new or significantly improved methods of manufacturing products or offering services

Table 5 presents the coefficients that are estimates obtained by binary logistic model. The results demonstrate that the odds of being innovative (introduce new product or service) by firms with all employees are professionals is 1.91 times higher than those firms with no professional employees. We find that training and skillful employees have a greater impact on introduction of new product or service. The odds of firms that trained all employees are three times higher than firms with no training to their employees. On the other hand, the odds of innovation level for firms that reported that they didn't face difficulties in production due to employees' shortage or skills gap is twice to that of firms face difficulties because of employees' shortage of skills. 
Table 5. Binary logit model - determinants of innovation

\begin{tabular}{lcc}
\hline & $(1)$ & $(2)$ \\
\hline VARIABLES & Logit coeff & Odds ratio \\
\hline Innovation & & \\
Professionals & $0.645^{* * *}$ & $1.906^{* * *}$ \\
& $(0.247)$ & $(0.471)$ \\
Training & $1.039^{* * *}$ & $2.826^{* * *}$ \\
& $(0.285)$ & $(0.804)$ \\
No skill shortage & $0.737^{* * *}$ & $2.090^{* * *}$ \\
& $(0.251)$ & $(0.525)$ \\
Medium & 0.616 & 1.852 \\
& $(0.429)$ & $(0.795)$ \\
Small & 0.217 & 1.242 \\
& $(0.407)$ & $(0.505)$ \\
Age3 & 0.333 & 1.395 \\
& $(0.562)$ & $(0.784)$ \\
Age2 & 0.693 & 1.999 \\
& $(0.579)$ & $(1.158)$ \\
Constant & $-1.373^{* *}$ & $0.253^{* *}$ \\
Observations & $(0.683)$ & $(0.173)$ \\
LR Chi2 $(7)=28.02$ & 345 & 345 \\
Prob $>$ Chi2 $=0.0002$ & & \\
\hline
\end{tabular}

Note. Standard errors in parentheses. $* * * \mathrm{p}<0.01, * * \mathrm{p}<0.05, * \mathrm{p}<0.1$.

\subsubsection{Sales Growth Performance}

Table 6 shows the estimations carried out using an ordinary least square regression model. The dependent variable is the logarithm of sales growth from 2013 to 2015. We control age with three categories: less than or equal to 5 years (age1-reference category), greater than 5 and less than or equal to 10 years (age2), and greater than 10 years (age3). The findings suggest that the age of the SML plays a role in their performance. Further, the region of operations also has an effect on the performance of the SML. We find that more professional employees and innovation in terms of introducing new products or services have a positive effect on sales growth. Surprisingly, the variable capturing skill is only significant at $10 \%$ and has a negative coefficient. A statistically significant positive coefficient for firm age variables in the regression confirms that older firms have more sales growth than their younger counterparts.

Table 6. Determinants of firms' sales performance

\begin{tabular}{|c|c|c|c|c|c|c|}
\hline Explanatory variables & Coefficients & Std. Err. & $\mathbf{t}$ & p value & \multicolumn{2}{|c|}{ [95\% conf. interval] } \\
\hline \multicolumn{7}{|l|}{ Size indicators } \\
\hline small & 0.0294 & 0.0449 & 0.66 & 0.513 & -0.0589 & 0.1177 \\
\hline medium & 0.0400 & 0.0469 & 0.85 & 0.394 & -0.0522 & 0.1323 \\
\hline age2 & 0.2247 & 0.0645 & 3.48 & 0.001 & 0.0977 & 0.3518 \\
\hline age3 & 0.1931 & 0.0631 & 3.06 & 0.002 & 0.0688 & 0.3173 \\
\hline \multicolumn{7}{|l|}{ Location indicators } \\
\hline Lusaka & 0.1607 & 0.0424 & 3.79 & 0.000 & 0.0772 & 0.2442 \\
\hline Kitwe & 0.2013 & 0.0485 & 4.15 & 0.000 & 0.1058 & 0.2969 \\
\hline Livingstone & 0.1143 & 0.0471 & 2.42 & 0.016 & 0.0215 & 0.2071 \\
\hline \multicolumn{7}{|l|}{ Education and skills indicators } \\
\hline$\%$ who completed TVET & 0.0008 & 0.0005 & 1.54 & 0.124 & -0.0021 & 0.0000 \\
\hline$\%$ with higher (tertiary) education & -0.0010 & 0.0005 & -1.80 & 0.073 & -0.0021 & 0.0000 \\
\hline professional employees & 0.0022 & 0.0009 & 2.42 & 0.016 & 0.0004 & 0.0040 \\
\hline constant & -0.4493 & 0.0823 & -5.46 & 0.000 & -0.0113 & 0.2873 \\
\hline Number of obs $=339$ & & \multicolumn{5}{|c|}{$\mathrm{R}$ squared $=0.1316$} \\
\hline $\mathrm{F}(10,328)=4.97$ & & \multicolumn{5}{|c|}{ Adj R squ. $=0.1051$} \\
\hline Prob $>F=0.0000$ & & & & & & \\
\hline
\end{tabular}


The educational attainment of the labour force in Zambia has affected the quality of skills that are available for most SML. In order to improve these skills, most firms depend on in-house training to get the required skills from their employees. However, it should be noted that most of the firms included in the sample are small in size. These usually employ few workers and are mainly interested in reducing their operating costs. They do not have an advantage of benefitting from economies of scale. In this regard, they usually employ workers that can be paid at a lower rate. Further, the form of business undertaken by these small firms does not require the workers to have high levels of skills.

\section{Conclusion}

In this paper, we estimate the impact of training, skills gap and firm-level factors on firms' innovation performance and sales growth using the WB Enterprise Survey Zambia 2016. The survey was conducted on 350 firms from four cities of Zambia. Like most African countries Zambia has low skills base and the problem is embedded in the economic structure that significantly affects the performance of firms. Employers often the time dissatisfied with their manpower because their acquired education, training and work experience is not as per the expected required for the tasks the workers assigned to handle. The weak skills stock in these countries led to low productivity and firms are less competitive internally and globally despite the rapidly changing labour market conditions and international trade. The workforce lack the capacity to plan, build, operate and maintain physical infrastructures and other capital assets (WB, 2008). This paper tries to establish a link between the stock of manpower skill and firm performance. Furthermore, an attempt is made to investigate which type of economic sector is most affected by a low level of skills.

Our empirical results show that a third of the firms took part in the survey reported that they have difficulties to maintain product quality, introducing new products or new technology adoption. We find that the number of professional employees, training, and absence of skill gap have a positive impact on innovation performance. The role of professional employees, innovation, age, and location of firms have a significant impact on sales growth. These results demonstrate that firms aim to be innovative or to increase sales growth have to exert more effort in training and employees' skills improvement.

We noted that most of the firms included in the sample are small in size. These usually employ few workers and are mainly interested in reducing their operating costs. They do not have an advantage of benefitting from economies of scale. They usually employ workers that can be paid at a lower rate. Further, the form of business undertaken by these small firms does not require the workers to have high levels of skills. Based on the information analyzed from the survey data, there is a need for government to put in place programs that will encourage skill development. This can be more effectively done by the government having constant interactions with the private sector to fully understand their required skills.

\section{References}

Ahmed, M. S., \& Ahmed, M. D. (2013). Efficiency Variation of Manufacturing Firms:A Case Study of Seafood Processing Firms in Bangladesh. Review of Economics and Finance.

Blundell, R., Dearden, L., Meghir, C., \& Sianesi, B. (1999). Human Capital Investment: The Returns from Education and Training to the Individual. The Firm and the Economy. Fiscal Studies, 20(1), 1-23.

Blyde, J. (2016). Exports and Labor Skills: The Role of Training. Munich Personal RePEc Archive: MPRA Paper No. 72150.

Burger, R., Rulof, B., \& Servaas, van der B. (2005). A Note on Trends in the Zambian Labour Market Between 1991 and 1998. Department of Economics, Stellenbosch University.

Central Statistical Office (CSO) [Zambia]. (2012). 2010 Census of Population and Housing National Analytical Report. Lusaka, Zambia: Central Statistical Office.

Central Statistics Office (CSO). (2013). Population and Demographic Projections 2011-2035. Lusaka.

Central Statistics Office. (2015). 2014 Labour Force Survey Report. Lusaka, Zambia: Central Statistics Office (CSO).

Dostie, B. (2014). Innovation, Productivity, and Training. IZA DP No. 8506.

Edjigu, H. T. (2016). Firm Growth and Technical Efficiency in Ethiopia: The Role of Firm Size and Finances. International Journal of Economics and Finance, 8(10). https://doi.org/10.5539/ijef.v8n10p1

Fluitman, F., \& Wim, A. (2000). Zambia. In G. Indermit, F. Fluitman, \& A. Dar (Eds.), Vocational Training and training reform: Matching skills to markets and budgets. Oxford and New York: Oxford University Press 
for the World Bank.

Government of the Republic of Zambia. (2011). Sixth National Development Plan 2011-2015. Lusaka, Zambia.

GRZ. (2006). Vision 2030: A Prosperous Middle Income Nation by 2030. Government of the Republic of Zambia.

Haskel, J., \& Martin, C. (1993). Do Skill Shortages Reduce Productivity? Theory and Evidence from the United Kingdom. The Economic Journal, 103(417). https://doi.org/10.2307/2234777

Jonathan, H., \& Christopher, M. (1993). The Causes of Skill Shortages in Britain. Oxford Economic Papers, New Series, 45(4). 573-588. https://doi.org/10.1093/oxfordjournals.oep.a042108

Manju, K. S. (2012). The Informal Sector in Zambia. Can it disappear? Should it disappear? F-41004-ZMB-1. Working paper. IGC.

Mincer, J. (1962). On-the-Job Training: Costs, Returns, and Some Implications. Journal of Political Economy, 70, (5), 50-79. https://doi.org/10.1086/258725

Ministry of Education. (2010). Education sector National Implementation Framework III 2011-2015. Lusaka, Zambia: Directorate of Planning.

Ministry of National Development Planning (2017). Seven National Development Plan 2017-2021, Lusaka: GRZ.

Moono, H., \& Rankin, N. (2013). Education and Employment in Zambia: Evidence from a Scoping Exercise. International Growth Centre Working Paper.

Rosenbusch, N., Brinckmann, J., \& Bausch, A. (2011). Is innovation always beneficial? A meta-analysis of the relationship between innovation and performance in SMEs. Journal of Business Venturing. https://doi.org/10.1016/j.jbusvent.2009.12.002

Soderbom, M., \& Teal, F. (2004). Size and Efficiency in African Manufacturing Firms: Evidence from Firm-Level Panel Data. Journal of Development Economics, 73, 369-394. https://doi.org/10.1016/j.jdeveco.2003.02.005

UIS (UNESCO Institute for Statistics). (2014). Zambia: National Assessment Survey. Examinations Council of Zambia. Retrieved from http://www.uis.unesco.org/nada/en/index.php/catalogue/112

UNESCO. (2016). Zambia. UNESCO Education Policy Review: Paving the way for SDG - 4 - Education Policy 2030. UNESCO.

World Bank (WB). (2016). Zambia Firm-level Skills Survey.

World Bank. (2015). World Bank Zambia Database 2015. Retrieved from http://data.worldbank.org/country/zambia?display=graph

World Bank. (2018). Retrieved from https://data.worldbank.org/indicator

Yang, D. et al. (2018). Open Innovation and Firm Performance: Evidence from the Chinese Mechanical Manufacturing Industry. Journal of Engineering and Technology Management, 48, 76-86. https://doi.org/10.1016/j.jengtecman.2018.04.004

\section{Copyrights}

Copyright for this article is retained by the author(s), with first publication rights granted to the journal.

This is an open-access article distributed under the terms and conditions of the Creative Commons Attribution license (http://creativecommons.org/licenses/by/4.0/). 